\title{
Classificação em estágios da doença renal crônica em cães e gatos - abordagem clínica, laboratorial e terapêutica
}

\author{
Classification into stages of chronic kidney disease in dogs and cats - clinical, laboratorial and \\ therapeutic approach
}

\author{
Mariana Faraone Waki ${ }^{I}$ Cínthia Ribas MartorelliII Patrícia Erdmann Mosko ${ }^{I I}$ \\ Márcia Mery Kogika ${ }^{\mathrm{I}^{*}}$
}

\section{- REVISÃO BIBLIOGRÁFICA -}

\section{RESUMO}

Foi proposta uma revisão das terminologias empregadas para a descrição das alterações renais e também sugerida uma classificação em estágios para a doença renal crônica à semelhança da medicina humana pela IRIS (International Renal Interest Society). Essa classificação considera os estágios da doença de acordo com o tempo de evolução e a presença de marcadores de lesão renal. O objetivo principal é auxiliar no estabelecimento do diagnóstico, do prognóstico e da terapia adequada conforme cada estágio e, assim, retardar a perda da função dos rins e a evolução da doença renal e, dessa forma, propiciar melhor qualidade de vida ao paciente.

Palavras-chave: cães, gatos, doença renal crônica, estágios.

\begin{abstract}
A terminology review was proposed in order to describe renal alterations as well as to suggest a classification according to the stages of chronic kidney disease by IRIS (International Renal Interest Society) which is similar to human medicine. That classification considers the stage of evolution of the disease and urinary markers of kidney damage findings. The main objective is to help to establish the diagnostic, the prognosis and the adequate therapy corresponding to each stage of the disease in order to delay loss of renal function and its progression, and then providing better quality of patient's life.
\end{abstract}

Key words: dogs, cats, chronic kidney disease, stages.

\section{INTRODUÇÃO}

Sempre foi de grande interesse a padronização dos termos e conceitos relativos às doenças renais crônicas em cães e gatos, com o intuito de auxiliar no diagnóstico, no prognóstico e no tratamento (BROWN, 1999). Tradicionalmente, os termos doença renal, insuficiência renal, falência renal, azotemia e uremia têm sido empregados como sinônimos para descrever processos patológicos renais, o que implica diagnóstico equivocado e muitas vezes ocasiona a indicação de terapia inadequada (POLZIN et al., 2005). As doenças renais podem acometer os glomérulos, os túbulos, o tecido intersticial e/ou os vasos sanguíneos, e as afecções podem ter origem hereditária/congênita, infecciosa e tóxica (toxinas endógena ou exógena), ser imunomediada, por desequilíbrios eletrolíticos (hipercalcemia e hipocalemia no felino), e traumática (POLZIN, 2008). O rim é um órgão de múltiplas funções orgânicas (excretória, regulatória e biossintética) (POLZIN et al., 2005) e, para preservar a homeostase, não é necessária a presença do número original de néfrons, mas sim o suficiente para manter as funções. A falência renal retrata a disfunção máxima do órgão, e a insuficiência renal designa os quadros em que há perda de função renal, mas há ainda a tentativa de compensação por meio da

'Departamento de Clínica Médica, Faculdade de Medicina Veterinária e Zootecnia (FMVZ), Universidade de São Paulo (USP). Av. Prof. Orlando Marques de Paiva, 87, 05508-270, São Paulo, SP, Brasil. E-mail: mmkogika@usp.br. *Autor para correspondência. IIPrograma de Pós-graduação em Clínica Médica, USP, São Paulo, SP, Brasil. 
reserva funcional dos rins, da ativação dos mecanismos de hipertrofia e da hiperplasia de néfrons (POLZIN et al., 2005; McGROTTY, 2008). A azotemia é detectada quando há perda funcional de aproximadamente $65 \mathrm{a}$ $75 \%$ dos néfrons em gatos e cães, respectivamente.

Atualmente, o termo Doença Renal Crônica (DRC) é utilizado para definir a presença de lesão renal persistente pelo período mínimo de três meses, caracterizada pela perda definitiva e irreversível de massa funcional e/ou estrutural de um ou de ambos os rins, e pode-se observar redução da taxa de filtração glomerular (TFG) de até $50 \%$ em relação ao seu normal (POLZIN et al., 2005; POLZIN, 2008). O diagnóstico da DRC é embasado na anamnese, no exame físico e nos achados laboratoriais (SANDERSON, 2009) e, ainda, pela presença de lesões estruturais nos rins (biópsia e/ou exames de imagem) (POLZIN et al., 2005). Ademais, a disfunção renal é avaliada por marcadores sanguíneos e urinários. As alterações laboratoriais que podem ser encontradas consistem em: aumento das concentrações séricas de ureia e creatinina, hiperfosfatemia, alterações eletrolíticas, acidose metabólica, hipoalbuminemia, anemia não regenerativa e aumento sérico de amilase e lipase (POLZIN et al., 2005; McGROTTY, 2008). Como marcador urinário, a isostenúria reflete a inabilidade renal em concentrar a urina. Esse achado pode ser uma das primeiras manifestações clínicas da DRC, principalmente em cães (McGROTTY, 2008). Outras variáveis incluem proteinúria, cilindrúria, hematúria renal, alterações do pH urinário, glicosúria renal e/ou cistinúria (POLZIN et al., 2005).

A DRC é uma afecção frequentemente diagnosticada em cães e gatos, com prevalência de 0,5 a $7 \%$ e 1,6 a $20 \%$, respectivamente; é uma das doenças mais comuns na espécie felina (LUND et al., 1999; WATSON, 2001; POLZIN, 2007). Embora não exista predileção racial e etária (POLZIN et al., 2004), sabe-se que a morbidade e mortalidade são predominantes nos pacientes, cães e gatos com idade mais avançada (LEES, 2004). Para o melhor entendimento da abordagem clínica da DRC, segundo os estágios de evolução, desde 2006, foi proposta uma nova terminologia pela IRIS (International Renal Interest Society), pois é uma doença de caráter progressivo, e a disfunção renal é proporcional à gravidade da doença, assim como o seu prognóstico (POLZIN, 2008). Assim, é de suma importância a diferenciação entre os estágios da DRC para se estabelecer condutas terapêuticas, a fim de melhorar a qualidade de vida, retardar a progressão da doença, aumentar a expectativa de vida e reduzir as complicações inerentes a sua evolução (POLZIN et al., 2009).
Classificação por estágios da doença renal crônica

A Sociedade Internacional de Interesse Renal (International Renal Interest Society - IRIS) propõe um sistema de classificação composto por quatro estágios de evolução da DRC em cães e em gatos (IRIS Staging System of CKD, 2009). Esses estágios foram estabelecidos principalmente de acordo com as concentrações séricas de creatinina, pois esse marcador de taxa de filtração glomerular (TFG) ainda é considerado a melhor variável laboratorial para emprego na rotina da clínica (POLZIN et al., 2005; SANDERSON, 2009). Os valores de creatinina sérica devem ser obtidos no paciente em jejum e hidratado, em dois ou três momentos diferentes ao longo de algumas semanas (POLZIN, 2008). É preciso excluir as variações de creatinina transitórias pré-renais ou pósrenais, mesmo que haja o diagnóstico já estabelecido de DRC, como também considerar a condição corpórea do paciente, especialmente a massa muscular, para evitar a ocorrência de classificação errônea (POLZIN et al., 2005).

O estágio I da DRC define-se por estado não azotêmico, mas há alguma alteração renal presente, tal como inabilidade renal de concentração urinária, proteinúria renal e alterações renais ao exame de imagem e de biópsia. O estágio II caracteriza-se pela presença de discreta azotemia em avaliações seriadas (creatinina sérica entre $1,4 \mathrm{mg} \mathrm{dL}^{-1}$ e $2,0 \mathrm{mg} \mathrm{dL}^{-1}$ para cães e de $1,6 \mathrm{mg} \mathrm{dL}^{-1}$ a $2,8 \mathrm{mg} \mathrm{dL}^{-1}$ para gatos). Pacientes nos estágios I e II não apresentam manifestações clínicas de disfunção renal, à exceção de poliúria e polidipsia. Ocasionalmente gatos com DRC em estágio II podem apresentar perda de peso e apetite seletivo; contudo, na presença de complicações da DRC, tais como pielonefrite e nefrolitíase, as manifestações clínicas podem se tornar mais evidentes (POLZIN et al., 2005). O estágio III é definido pela presença de azotemia em grau moderado (creatinina sérica entre $2,1 \mathrm{mg} \mathrm{dL}^{-1} \mathrm{e}$ $5,0 \mathrm{mg} \mathrm{dL}^{-1}$ para cães e de $2,9 \mathrm{mg} \mathrm{dL}^{-1}$ a $5,0 \mathrm{mg} \mathrm{dL}^{-1}$ para gatos). O paciente poderá apresentar manifestações sistêmicas da perda de função renal. A progressão da DRC nos pacientes desse estágio geralmente está ligada aos mecanismos de progressão espontânea da doença (autoperpetuação), mas pode também se relacionar às causas desencadeantes. $\mathrm{O}$ estágio IV caracteriza-se pela presença de intensa azotemia (creatinina sérica superior a $5,0 \mathrm{mg} \mathrm{dL}^{-1}$ para cães e gatos). Nesse estágio, o paciente apresenta importante perda da função renal que pode estar relacionada à falência renal e apresentar diversas manifestações sistêmicas da uremia como, por exemplo, alterações gastrintestinais, neuromusculares ou cardiovasculares. 
Ainda, na classificação proposta pela IRIS (2009), há os subestágios e esses estão relacionados à proteinúria renal e à hipertensão arterial sistêmica, considerados como fatores independentes de progressão da DRC (LEES et al., 2005; GRAUER, 2007; BACIC et al., 2010) e que interferem no prognóstico e requerem intervenção terapêutica específica (POLZIN, 2008). Constata-se que pacientes com proteinúria e/ou hipertensão podem apresentar manifestações clínicas relacionadas a esses aspectos já nos estágios precoces da doença, assim como podem progredir rapidamente para maior perda de massa renal funcional (POLZIN, 2008; POLZIN et al., 2009).

A classificação do paciente como proteinúrico, como também a preconização inicial de terapia específica, deve ser realizada somente após a identificação e exclusão de fatores pré e pós-renais de perda urinária de proteína e, ainda, a confirmação de sua persistência pela determinação do valor da razão proteína/creatinina urinária (RPC) em diferentes momentos ou atendimentos clínicos (duas a três ocasiões com intervalo mínimo de 15 dias) (POLZIN, 2008). A determinação da RPC é indicada devido à necessidade de classificar a magnitude da proteinúria, o que não é possível com o método de química seca, utilizado na fita reagente. A RPC é um método considerado quantitativo, e o método padrão-ouro é determinado pela técnica em que se utiliza o corante azul brilhante de Coomassie (BRADFORD, 1976; LEES et al., 2005; GRAUER, 2007). O aumento do valor da RPC pode ocorrer com a progressão da DRC, assim como diminuir em reposta à terapia específica. Os pacientes classificados com proteinúria de valores limítrofes ou suspeitos devem ser reavaliados após dois meses para sua correta classificação (POLZIN, 2008). Com relação à pressão arterial, valores de pressão arterial sistólica acima de 150 a $160 \mathrm{mmHg}$ já podem apresentar risco para o desenvolvimento de lesões de órgãos-alvo, tais como olhos, rins, coração e cérebro (BROWN et al., 2007).

Com a classificação em estágios da DRC, é possível estabelecer condutas terapêuticas, baseadas nas considerações da fisiopatologia da progressão da DRC e na experiência clínica. A investigação e monitoração ambulatorial e laboratorial dos pacientes ao longo do curso da doença são indicadas para detectar e prevenir a progressão da doença, bem como possibilitar a correção das possíveis alterações orgânicas (ELLIOTT \& WATSON, 2009).

Abordagem terapêutica segundo os estágios da doença renal crônica

No estágio I, os marcadores de lesão renal já indicam o comprometimento dos rins na ausência de azotemia renal. Nesse estágio, é importante manter o animal hidratado, permitindo acesso livre para a ingestão de água, como também corrigir, quando necessário, a desidratação e assim evitar etiologias adicionais para lesão renal aguda.

A proteinúria pode ocorrer em qualquer estágio da DRC e, uma vez confirmada a sua magnitude, o tratamento é recomendado quando a RPC apresenta valores superiores a 2,0 no estágio I. A terapia indicada tem o intuito de modular a pressão intraglomerular por meio do uso de inibidores da enzima conversora da angiotensina (iECA), como enalapril ou benazepril, e tem por objetivo a redução da proteinúria para valores de RPC inferiores a 1,0 ou de pelo menos $50 \%$ do valor inicial da magnitude observada (POLZIN, 2008). Uma vez que a proteinúria é considerada um marcador de lesão renal, a redução da sua intensidade pode ser benéfica, principalmente nos estágios mais precoces da DRC (LEES et al., 2005). Quando não ocorre a resposta adequada ao iECA, poderá ser necessário o uso de bloqueadores de receptor de angiotensina II, como losartan ou irbesartan. Para os cães, a dose recomendada do losartan é de 0,25 a $0,5 \mathrm{mg} \mathrm{kg}^{-1} \mathrm{dia}^{-1}$, até a dose máxima de $01 \mathrm{mg} \mathrm{kg}^{-1}$ a cada 12 horas (POLZIN, 2007); entretanto, deve-se ressaltar que esses fármacos ainda são de pouco uso na medicina veterinária. Ainda é importante lembrar que a resposta ao tratamento da proteinúria em cães e gatos é classificada como sendo de grau 4, segundo a Medicina Baseada em Evidência. Isso significa que ainda há fraco suporte científico para sua recomendação, uma vez que não há estudos científicos suficientes que atestem cabalmente essa indicação. Portanto, as indicações atuais são embasadas na experiência clínica e nas informações obtidas da medicina humana e justificadas pela fisiopatologia (POLZIN, 2007).

A hipertensão arterial sistêmica (HAS) também pode ocorrer em qualquer estágio da DRC. Os valores da pressão arterial sistêmica devem ser confirmados após três aferições realizadas em momentos ou atendimentos diferentes. A terapia deve ser instituída se a pressão arterial exceder 180/120 mmHg em cães e gatos, no estágio I. Nos casos em que existem evidências de retinopatia hipertensiva ou lesões centrais, a terapia deve ser instituída na primeira avaliação (POLZIN et al., 2009). O principal objetivo do tratamento é reduzir gradualmente a pressão arterial $(<160 / 100 \mathrm{mmHg})$ no intuito de evitar lesões dos órgãosalvo e súbita hipotensão (POLZIN, 2007; ELLIOTT \& WATSON, 2009). Em felinos, a terapia de eleição é os bloqueadores de canais de cálcio, como o besilato de amlodipina, na dose de $0,625 \mathrm{mg} \mathrm{gato}^{-1}$ de até $5 \mathrm{~kg}$ de peso e $1,25 \mathrm{mg} \mathrm{gato}^{-1}$, com peso acima de $5 \mathrm{~kg}$ (POLZIN, 
2007); caso não haja uma resposta adequada, a dose pode ser dobrada. A eficiência do uso de bloqueadores de canal de cálcio é considerada de grau 2, segundo a Medicina Baseada em Evidência, ou seja, de que a indicação foi originada de estudos em modelos laboratoriais ou na própria espécie, mas em condições ideais e que pode ou não representar a verdadeira eficácia para os casos de evolução natural da doença (POLZIN, 2007).

Nos cães, a terapia anti-hipertensiva baseiase num conjunto de ações, pois raramente a monoterapia é suficiente para o controle (BARTGES et al., 1996). Recomenda-se o emprego de inibidores da enzima de conversão da angiotensina (iECA), na dose de $0,25 \mathrm{a} 0,5 \mathrm{mg} \mathrm{kg}^{-1}$ (ou até $3 \mathrm{mg} \mathrm{kg}^{-1}$ ). O aumento gradual da dose deve ser realizado com cautela por meio da monitoração da taxa de filtração glomerular (TFG), avaliada pela concentração sérica de creatinina, uma vez que ocorre a redução da pressão intraglomerular e, portanto, a diminuição da TFG mesmo quando não há diminuição da pressão arterial sistêmica. Os bloqueadores de canal de cálcio, como a amlodipina, podem ser utilizados em associação com os iECA, quando necessário, na dose de 0,1 a $0,6 \mathrm{mg} \mathrm{kg}^{-1}$, até a redução da pressão sistólica. Deve-se monitorar a pressão arterial semanalmente até que os valores atinjam níveis normais e, posteriormente, no intervalo de três a quatro meses (POLZIN, 2007).

$\mathrm{O}$ uso de iECA, tanto para controle da proteinúria, quanto para controle da HAS, pode ocasionar o aumento discreto de $0,5 \mathrm{mg} \mathrm{dL}^{-1}$ nos níveis séricos de creatinina, no início da terapia, mas esperase o retorno das concentrações iniciais em cinco a sete dias. Quando se observa o aumento repentino da concentração sérica de creatinina, esse fato pode estar relacionado com o efeito colateral do fármaco, enquanto que o aumento gradativo sugere a existência de comprometimento intrínseco da função renal (ELLIOTT \&WATSON, 2009). Recomenda-se, também, que sejam realizadas as determinações séricas de potássio e sódio para uma avaliação indireta da ação do sistema reninaangiotensina-aldosterona (SCHRIER \& REGAL, 1972).

No estágio II, a desidratação pode estar presente e geralmente ocorre de forma pontual em algum momento em que ocorreu a limitação quanto à ingestão de água ou a perda de água por processos gastrentéricos, por exemplo (POLZIN, 2008). As manifestações clínicas associadas à desidratação incluem disorexia, letargia, fraqueza e constipação principalmente em gatos, e a azotemia pré-renal pode predispor à lesão renal aguda (POLZIN, 2008). No estágio II, é possível detectar alterações decorrentes dos fatores de progressão da doença renal, tais como o hiperparatireoidismo secundário/hiperfosfatemia, acidose metabólica e hipocalemia, e esta última é mais frequente no felino. Ainda, a retenção de fósforo no sangue ocorre de forma gradativa devido à diminuição progressiva da taxa de filtração glomerular. Especificamente nos felinos pode-se observar o aumento da concentração sérica de paratormônio $(\mathrm{PTH})$, mesmo na presença de concentrações séricas de fósforo na faixa de normalidade (KIDDER \& CHEW, 2009). O objetivo, no estágio II da DRC, é manter as concentrações séricas de fósforo inferiores a $4,5 \mathrm{mg}$ $\mathrm{dL}^{-1}$, o que pode ser obtido apenas com o uso de dieta hipofosfórica (ELLIOTT, 2006; POLZIN, 2007 e 2008).

Ainda no estágio II pode-se observar também acidose metabólica que ocorre em consequência do comprometimento renal na excreção de ácidos, na reabsorção de bicarbonato (HCO ), como também pelo processo de amoniagênese renal (P̉OLZIN et al., 2009). Dessa forma, é indicado determinar o valor do bicarbonato sanguíneo para assim estabelecer medidas terapêuticas necessárias. No cão, a administração de bicarbonato por via oral é recomendada quando o $\mathrm{HCO}_{3}{ }^{-}$sanguíneo for $<18 \mathrm{mEq}$ $\mathrm{L}^{-1}$ e no gato quando $<16 \mathrm{mEq} \mathrm{L}^{-1}$ (ELLIOTT \& WATSON, 2009). Vale ressaltar que os felinos desenvolvem a acidose em estágios anteriores quando comparados aos cães, e esse fato pode estar relacionado com a capacidade maior de absorção renal de bicarbonato que os cães apresentam (POLZIN et al., 1995; POLZIN et al., 2000). A dose inicial de bicarbonato para suplementação oral é de 0,5 a $1,0 \mathrm{mEq}$ $\mathrm{kg}^{-1} \mathrm{dia}^{-1}$ ou 8 a $12 \mathrm{mg} \mathrm{kg}^{-1}$ a cada 8 a 12 horas; esta pode ser realizada por meio de uma solução preparada com um litro de água e $84 \mathrm{mg}$ de bicarbonato em pó, resultando em uma concentração de $1 \mathrm{mEq} \mathrm{mL}^{-1}$. Indicase a administração de 1,0 a $1,5 \mathrm{~mL} 10 \mathrm{~kg}^{-1}$ de peso por via oral (POLZIN \& OSBORNE, 1995). Ainda, a dose deve ser fracionada para evitar os efeitos gástricos do bicarbonato (POLZIN \& OSBORNE, 1995; POLZIN, 2007). A indicação do citrato de potássio também pode ser benéfica nos pacientes que apresentam concomitantemente hipocalemia e acidose. A reposição de potássio deve ser preconizada com cautela, uma vez que existe diferença entre a dose de reposição e aquela empregada para correção de acidose, para assim prevenir o desenvolvimento de alcalemia. Após normalização dos valores sanguíneos de bicarbonato, a monitoração deve ser realizada a cada três ou quatro meses para o controle adequado (POLZIN, 2007).

Quanto aos felinos com DRC no estágio II, estes apresentam maior possibilidade de desenvolver hipocalemia, resultante da diminuição da ingestão de potássio e do aumento da perda urinária e suscita-se, 
ainda, a possibilidade de que a dieta hipossódica oferecida para esses pacientes possa de certa forma ativar o sistema renina-angiotensina-aldosterona (POLZIN et al., 2009). A hipocalemia crônica acomete 20 a $30 \%$ dos gatos com DRC e pode comprometer em graus variados a função do rim e das musculaturas cardíaca e esquelética. As manifestações clínicas provenientes da hipocalemia ocorrem quando a concentração de potássio é inferior a $2,5 \mathrm{mEq} \mathrm{L}^{-1}$. A melhor escolha para a reposição oral de potássio é o gluconato de potássio, apresentação mais palatável, na dose de $2 \mathrm{mEq}$ para cada $4,5 \mathrm{~kg}$ de peso, administrado duas vezes ao dia juntamente com o alimento (MAY \& LANGSTON, 2006). Quanto ao citrato de potássio, a dose recomendada é de 40 a $60 \mathrm{mg} \mathrm{kg}^{-1} \mathrm{dia}^{-1}$ dividida em duas a três administrações (MAY \& LANGSTON, 2006). Para a suplementação parenteral de potássio, recomendado nos casos de discreta hipopotassemia no estágio II, é preconizado o cloreto de potássio, pela via subcutânea, juntamente com o fluido na concentração de até $35 \mathrm{mEq} \mathrm{L}^{-1}$ (LANGSTON, 2008). Uma vez obtida a concentração sérica de potássio entre os valores de 3,5 a 5,5 $\mathrm{mEq} \mathrm{L}^{-1}$, recomenda-se a avaliação desse eletrólito a cada três ou quatro meses (POLZIN, 2007).

Ainda no estágio II, a hipertensão arterial também pode estar presente, e a recomendação do uso de anti-hipertensivos, conforme os fármacos já descritos para o estágio I, é indicada quando a pressão arterial for superior a $160 / 100 \mathrm{mmHg}$; esse procedimento também é preconizado para os estágios III e IV (POLZIN, et al., 2009).

Quanto à proteinúria, a terapia é indicada quando os valores da RPC forem superiores a 0,5 e 0,4 para os cães e gatos, respectivamente, com azotemia (estágios II, III e IV) (POLZIN, 2007). Entretanto, é importante ressaltar que, apesar de alguns estudos, principalmente em gatos, indicarem os efeitos benéficos, tais como o aumento do tempo de vida dos gatos com DRC que receberam iECA, ainda não está estabelecido, à semelhança nos humanos, de qual seria o grau de proteinúria a ser alcançado com a terapia e que efetivamente evitaria o desenvolvimento de lesões renais decorrentes da proteinúria. Portanto, estudos futuros serão necessários para a conclusão dessas hipóteses; atualmente, a indicação da terapia antiproteinúrica encontra-se no grau 4 da Medicina Baseada em Evidência.

Para os estágios I e II da DRC, é importante estar atento para doenças que evoluem concomitantemente e que podem favorecer a perda precoce da função renal, tais como pielonefrite, hipertensão arterial sistêmica, diabetes mellitus, nefrolitíase, glomerulopatia/ glomeruloesclerose associada à proteinúria, ureterolitíase, entre outras (MAY \& LANGSTON, 2006).

No estágio III, todas as alterações laboratoriais mencionadas nos estágios I e II ocorrem de forma mais marcante, inclusive com manifestações clínicas, tornando-se necessária a introdução de terapia mais intensa. A desidratação nesse estágio ocorre de forma crônica e não mais pontual. Ademais, os rins apresentam comprometimento importante da função tubular de reabsorção de água, resultando em poliúria mais intensa do que a polidipsia compensatória. Além disso, esses pacientes podem apresentar azotemia prérenal associada, o que favorece o desenvolvimento de lesão renal por má perfusão, originada por causas diversas de desidratação (como vômito, diarreia, febre, limitação ao acesso a ingestão de água, estresse, etc). A desidratação per si é responsável pelas manifestações clínicas, tais como prostração, fraqueza, constipação (principalmente no felino) e perda de apetite. Assim, é primordial a correção da desidratação com a fluidoterapia de manutenção pela via parenteral (subcutânea) com uso de cristaloides (soluções de Ringer com lactato ou de $\mathrm{NaCl}$ - fisiológica $0,9 \%$ ). O volume de manutenção a ser administrado varia de acordo com o peso; para gatos e cães de pequeno porte, indica-se a administração diária de 75 a 150mL (POLZIN et al., 2005; MAY \& LANGSTON, 2006; POLZIN, 2007). Para os cães, recomenda-se 40 a $60 \mathrm{~mL}$ $\mathrm{kg}^{-1} \mathrm{em} 24$ horas, na dependência do porte do animal, e o intervalo de administração seria de acordo com a avaliação da intensidade da poliúria, da ingestão de água e do quadro clínico diário do paciente (BENESI \& KOGIKA, 2002; MAY \& LANGSTON, 2006). Há perda de vitaminas hidrossolúveis com a poliúria e, assim, recomenda-se a suplementação de vitaminas do complexo B (POLZIN \& OSBORNE, 1995; PLOTNICK, 2007).

Durante a fluidoterapia, pode ocorrer o desenvolvimento de hipocalemia, hipertensão e hipernatremia, como também esta comprometer a hemodinâmica e a função cardíaca. Assim, é necessária a monitoração estreita do paciente durante o tratamento, assim como a reavaliação da terapia sempre que necessário (POLZIN et al., 2009).

Quanto ao tratamento da proteinúria e da hipertensão arterial sistêmica, a recomendação é a mesma descrita para os estágios I e II, e deve-se ter cautela quanto ao uso de fármacos que comprometam a taxa de filtração glomerular (exemplo: iECA e diuréticos); portanto, a monitoração da concentração de creatinina sérica deve ser mais frequente.

Ciência Rural, v.40, n.10, out, 2010. 
Com o progredir da DRC, como reflexo da uremia, há comprometimento gradativo da condição corporal e do peso, disorexia, anorexia e perda da qualidade de vida. A desnutrição é a maior causa de morbidade e mortalidade em cães e gatos com DRC nos estágios III e IV, e nesse momento a introdução da dieta terapêutica é fortemente indicada, considerada como sendo de grau 1 da Medicina Baseada em Evidência (POLZIN, 2007). Os gatos com DRC já no estágio II, em comparação com os cães, necessitam de especificações nutricionais que previnam o desenvolvimento da uremia e a manutenção do escore corporal entre 4-5/9 (MAY \& LANGSTON, 2006; POLZIN, 2007). Assim, a dieta para o paciente com doença renal deve conter mais do que simplesmente baixos níveis de proteínas e ser composta de proteínas de alto valor biológico em teores adequados e que assegurem menor formação de compostos nitrogenados não proteicos. Ainda, a dieta deve conter baixo nível de sódio para evitar a hipertensão, como também fibras que atuam como substrato para bactérias que utilizam a ureia como fonte de crescimento, além de ácidos graxos (Ômega-3) para reduzir inflamação (ELLIOTT, 2006).

A restrição de fósforo na dieta colabora para a redução da progressão da DRC e aumenta o tempo de vida. A indicação de dieta hipofosfórica encontrase no estudo da Medicina Baseada em Evidência no grau 2 para cães e no grau 4 para gatos. Esta restrição tem o objetivo de manter os valores séricos de fósforo abaixo de $4,5 \mathrm{mg} \mathrm{dL}^{-1}$ no estágio II, de $5,0 \mathrm{mg} \mathrm{dL}^{-1}$ no estágio III e de $6,0 \mathrm{mg} \mathrm{dL}^{-1}$ no estágio IV; contudo, alguns pacientes do estágio III e a maioria do estágio IV necessitam do uso de quelantes de fósforo para atingir esse objetivo (POLZIN, 2008). Entre os quelantes, o mais recomendado é o hidróxido de alumínio, administrado junto com o alimento ou logo após a refeição, na dose de $30 \mathrm{a} 90 \mathrm{mg} \mathrm{kg}^{-1} \mathrm{dia}^{-1}$ (MAY \& LANGSTON, 2006). Outros quelantes de fósforo, tais como o carbonato de cálcio, também apresentam ação efetiva, mas podem causar hipercalcemia e calcificação metastática; a dose recomendada é de 90 a $150 \mathrm{mg} \mathrm{kg}^{-1} \mathrm{dia}^{-1}$ (POLZIN et al., 2005). Recomenda-se que a avaliação laboratorial do fósforo sérico seja realizada entre duas e quatro semanas após o início do tratamento (MAY \& LANGSTON, 2006) e, após atingir o valor de fósforo adequado, a avaliação laboratorial deve ser realizada a cada três ou quatro meses (POLZIN, 2007).

O calcitriol é indicado nos pacientes em estágio III ou IV, com a finalidade de reduzir um dos fatores desencadeantes do hiperparatireoidismo renal secundário, a deficiência de vitamina $\mathrm{D}_{3}$ ativa (POLZIN et al., 2009). Existe forte evidência clínica (grau 1 na Medicina Baseada em Evidência) para a utilização do calcitriol em cães, pois reduz a mortalidade, porém para gatos ainda não foi comprovada. Contudo essa terapia não deve ser iniciada até que os níveis séricos de fósforo estejam com valor abaixo de $6 \mathrm{mg} \mathrm{dL}^{-1}$ (MAY \& LANGSTON, 2006; POLZIN et al., 2009). A dose indicada é de 1,5 a $3,5 \mathrm{ng} \mathrm{kg}^{-1} \mathrm{dia}^{-1}$. A monitoração deve ser realizada pela mensuração sérica do PTH, do cálcio iônico e do fósforo, com a finalidade de se evitar a hipercalcemia (ELLIOTT \& WATSON, 2009).

Ainda no estágio III, atenção especial deve ser direcionada à acidose metabólica, pois essa condição, além de causar aumento do catabolismo proteico, também está relacionada com as alterações cardiovasculares, a desmineralização óssea, a osteodistrofia renal, a exacerbação da azotemia, o aumento do catabolismo de proteína da musculatura esquelética e as alterações do metabolismo intracelular, além do aumento da amoniagênese renal e da consequente lesão das células tubulares (POLZIN et al., 2004; ELLIOTT, 2006; POLZIN, 2007). Caso o uso de alcalinizantes por via oral não apresente resposta adequada, será necessária a indicação de administração de bicarbonato de sódio pela via intravenosa quando os valores de bicarbonato forem inferiores a $12 \mathrm{mEq} \mathrm{L}^{-1}$ (LANGSTON, 2008). É importante ressaltar que a dose a ser administrada deve ser calculada baseada nos valores de bicarbonato sanguíneo, e a dose inicial seria a metade ou um terço da dose total do déficit calculado; é importante a monitoração da terapia pela hemogasometria (CHEW \& GIEG, 2006). Para o cálculo do déficit de bicarbonato, recomenda-se a utilização do valor inferior de normalidade para a espécie, evitando-se assim o possível desenvolvimento de alcalemia. Deve-se, também, controlar a velocidade de infusão do fluido com o bicarbonato (CHEW \& GIEG, 2006). O bicarbonato não deve ser adicionado às soluções de Ringer ou de Ringer com lactato.

A anemia compromete a qualidade de vida dos cães e gatos nos estágios III a IV da DRC. O tratamento é indicado quando o hematócrito for inferior a $20 \%$ e o paciente apresentar manifestações clínicas que possam ser atribuídas à anemia, tais como perda de apetite, letargia e fraqueza. O objetivo é de manter os valores do hematócrito entre 30 e $40 \%$ em gatos e de 38 a 48\% em cães (POLZIN et al., 2005; MAY \& LANGSTON, 2006; POLZIN, 2007, 2008; NELSON \& COUTO, 2009). É importante ressaltar a necessidade de se investigar outras causas da anemia como má nutrição, hiperparatireoidismo, infecção concomitante, deficiência de ferro, etc. $\mathrm{O}$ tratamento com eritropoetina disponível seria a recombinante humana (50 a 100UI 
$\mathrm{kg}^{-1}$ de duas a três vezes por semana), mas que pode apresentar efeitos colaterais, tais como hipertensão sistêmica, hipercalemia, convulsões, além da produção de anticorpos antieritropoetina. A darbepoetina, ainda não disponível no Brasil, parece ter uma ação melhor e inclusive causa menor estímulo para a produção de anticorpos (POLZIN, 2008). A monitoração do hematócrito durante a terapia é importante para evitar a policitemia, como também para diminuir a dose da eritropoetina quando alcançado o valor esperado do hematócrito; a suplementação de ferro também deve ser considerada e realizada com critério para que esse mineral possa ser mais bem absorvido e disponibilizado. A dose recomendada para suplementação de ferro em cães e gatos é de 100 a $300 \mathrm{mg} \mathrm{dia}^{-1}$ e de 50 a $100 \mathrm{mg} \mathrm{dia}^{-1}$, respectivamente (COWGILL, 1995); as doses podem ser maiores na dependência do grau de anemia e dosagem da eritropoetina, uma vez que a eritropoetina promove maior mobilização de ferro para efetuar a hemoglobinização (PLOTNICK, 2007). Além disso, a suplementação com vitaminas do complexo B (ácido fólico, etc) também é indicada (POLZIN et al., 2005).

Ainda no estágio III da DRC, devido à uremia, vários sistemas podem ser acometidos e assim comprometer o estado geral. Náusea, vômitos, diarreia e diminuição do apetite podem ser controlados com o uso de bloqueadores de $\mathrm{H} 2$ (ranitidina, famotidina), antieméticos (metoclopramida, ondansetrona, meropitant - ainda não disponível no Brasil) e protetores de mucosa (sucralfato). Deve-se ainda recalcular a dose de fármacos que apresentam excreção renal, para assim evitar a superdosagem.

A evolução final da DRC compreende o estágio $I V$, fase em que o número de néfrons encontrase muito reduzido e assim comprometendo sobremaneira as várias funções dos rins. A manifestação clínica é mais exacerbada e também mais refratária à terapia. O tratamento da desidratação (reposição e manutenção com a fluidoterapia), o controle da hiperfosfatemia (manter as concentrações de fósforo $<6,0 \mathrm{mg} \mathrm{dL}^{-1}$ tanto para cães como para gatos) (POLZIN, 2008; ELLIOTT \& WATSON, 2009), da acidose metabólica e da anemia seguem as mesmas recomendações descritas para o estágio III. A nutrição enteral e/ou parenteral pode ser indicada na tentativa de manter o balanço nitrogenado positivo. A oligúria e a hipercalemia podem ser observadas nessa fase, e a crise urêmica ser mais evidente. É preciso compreender que se trata de uma fase em que a possibilidade dos néfrons remanescentes hiperfuncionantes preservar a função renal é remota. A indicação de hemodiálise na crise urêmica poderia ser proposta, mas com a ciência de ocorrer melhora somente temporária, pois haverá novamente o acúmulo das toxinas urêmicas, uma vez que os néfrons remanescentes não são em número e em de capacidade suficiente para recuperar a função renal.

Quanto ao transplante renal com o intuito e a esperança de obter novamente a função renal, os estudos publicados não são uniformes quanto ao momento da indicação do transplante e esse fato compromete a análise retrospectiva e prospectiva dos casos. É importante ressaltar que, após o procedimento, ainda há possibilidade de ocorrer a rejeição (nos gatos descrito em $13,1 \%$ dos casos); o tempo de sobrevida observado foi de $59 \%$ após seis meses e de $41 \%$ após três anos do procedimento, tempo semelhante ao observado também nos gatos que receberam somente a terapia de manutenção, à base de dieta balanceada $\mathrm{e}$ medicamentos (ADIN et al., 2001). Ainda, a terapia de imunossupressão (ciclosporina e corticosteróides) pós-transplante (BERNSTEEN et al., 2000) pode predispor ao desenvolvimento de infecções (toxoplasmose, peritonite infecciosa felina) e neoplasias (linfoma) (KATAYAMA\& MCANULTY, 2002). Também há a necessidade de se avaliar o aspecto ético sobre o doador (KATAYAMA \& MCANULTY, 2002). Portanto, esse procedimento ainda merece muita discussão, análise e reflexão.

\section{CONSIDERAÇÕES FINAIS}

A avaliação clínica e laboratorial do paciente com DRC, nos diferentes estágios da evolução da doença, pode auxiliar na melhor indicação de terapia de prevenção e manutenção, com os objetivos de diminuir a velocidade de progressão da doença e alcançar melhor qualidade de vida.

\section{REFERÊNCIAS}

ADIN, C.A. et al. Diagnostic predictors of complications and survival of renal transplantation in cats. Veterinary Surgery, v.30, p.515-521, 2001. Disponível em: <http:// onlinelibrary.wiley.com/10.1053/jvet.2001.28418>. Acesso em: 30 ago. 2010.

BACIC, A. et al. Evaluation of albuminuria and its relationship with blood pressure in dogs with chronic kidney disease. Veterinary Clinical Pathology, p.1-7 Published Online: 4 Jan 2010 (Article in advance of print). Disponível em: <http:/ /www3.interscience.wiley.com/cgi-bin/fulltext/123232492/ PDFSTART>. Acesso em: 3 maio, 2010. doi:10.1111/j.1939165X.2009.00207.x.

BARTGES, J.W. et al. Hypertension and renal disease. Veterinary Clinics of North America: Small Animal Practice, v.26, p.1331-1345, 1996. 
BENESI, F.J.; KOGIKA, M.M. Fluidoterapia. In: SPINOSA, H.S. et al. Farmacologia aplicada a medicina veterinária. Rio de Janeiro: Guanabara Koogan, 2002. p.652-678.

BERNSTEEN, L. et al. Renal transplantation in cats. Clinical Techniques in Small Animal Practice, v.15, n.01, p.4045, 2000. Disponível em: <http://www.sciencedirect.com/ science?_ob=ArticleURL\&_udi=B 75 B B-4GK2 NBJ $8 \&$ \& user $=5674931 \&$ _coverDate $=02 \% 2$ F $29 \% 2$ F $2000 \&$ _rdoc $=1 \&$ fmt=high\&_orig=search\&_origin=search\&_sort=d\&_ docanchor $=\&$ view $=$ c\&_searchStrId $=1445338527$ \& rerunOrigin $=$ scholar.google $\&$ acct $=\mathrm{C} 000049650$ vers i o $n=1 \&$ _ u r l Version $=0 \&$ \& userid=5674931\& md5=a1 d01e39697f4424c7ad862234fb27bc\&searchtype $=a>$. Acesso em: 30 ago. 2010. doi:10.1053/svms.2000.7303.

BRADFORD, M.M. A rapid and sensitive method for the quantification of microgram quantities of protein utilizing the principle of protein-dye binding. Analytical Biochemistry, v.72, p.248-254, 1976.

BROWN, S. Evaluation of chronic renal disease: A staged approach. Compendium on Continuing Education for the Practicing Veterinarian, v.21, p.752, 1999.

BROWN, S. et al. Guidelines for the identification, evaluation, and management of systemic hypertension in dogs and cats. Journal of Veterinary Internal Medicine, v.21, p.542558, 2007. Disponível em: <http://onlinelibrary.wiley.com/ doi/10.1111/j.1939-1676.2007.tb03005.x/abstract>. Acesso em: 30 ago. 2010.

CHEW, D.J.; GIEG, J.A. Fluid therapy during intrinsic renal failure. In: DIBARTOLA, S.P. Fluid, electrolyte and acidbase disorders in small animal practice. St. Louis: Saunders Elsevier, 2006. p.518-540.

COWGILL, L.D. Medical management of the anemia of chronic renal failure. In: OSBORNE, C.A.; FINCO, D.R. Canine and feline nephrology and urology. United States of America: Williams \& Wilkins, 1995. p.539-554.

ELLIOTT, D.; LEFEBVRE, H. Chronic renal disease: the importance of nutrition. In: PIBOT, P. et al. Encyclopedia of canine clinical nutrition. France: Edta. Aniwa SAS on behalf of Royal Canin, 2006. p.252-282.

ELLIOTT, J.; WATSON, A.D.J. Chronic kidney disease: staging and management. In: BONAGURA, J.D.; TWEDT, D.C. Kirk's current veterinary therapy XIV. St. Louis: Saunders Elsevier, 2009. p.883-891.

GRAUER, G.F. Measurement, interpretation, and implications of proteinuria and albuminúria. Veterinary Clinics of North America: Small Animal Practice, v.37, p.283-295, 2007. Disponível em: <http://linkinghub.elsevier.com/retrieve/pii/ S0195-5616(06)00138-0>. Acesso em: 30 ago. 2010.

IRIS Staging of CKD, 2009. Disponível em: http://www.iriskidney.com/guidelines/en/staging_ckd.shtml. Acesso em: 07 abr. 2010 .

KATAYAMA, M.; MCANULTY, J.E. Renal transplantation in cats: techniques, complications and immunosuppression. Compendium on Continuing Education for the Practicing Veterinarian, v.24, n.11, p.874-882, 2002.
KIDDER, A.; CHEW, D. Treatment options for hyperphosphatemia in feline CKD What's out there? Journal of feline medicine and surgery, v.11, p.913-924, 2009. Disponível em: <http:// www.sciencedirect.com/science?_ob=ArticleURL\&_udi=B6WJC4 XHVD 8 S $-4 \&$ \& user $=5674931 \&$ _coverDate $=11 \% 2$ F 30 $\% 2$ F $2009 \&$ \&doc $=1 \&$ _fmt $=$ high\&_orig $=$ search \& _origin $=$ search\&_sort $=\mathrm{d} \&$ _docanchor $=\& \mathrm{view}=\mathrm{c} \&$ \&searc hStrId=1445350794\&_rerunOrigin $=$ scholar.google \&_acct=C000049650 _version $=1 \&$ \&_urlVersion $=0 \&$ \& userid $=5674931 \&$ md5 $=4 \mathrm{cb} 7 \mathrm{e} 6 \mathrm{c} 88529 \mathrm{fc} 0 \mathrm{cb} 85 \mathrm{f} 37 \mathrm{ac} 4 \mathrm{f} 09 \mathrm{~b} 13 \mathrm{c} \&$ searchtype $=\mathrm{a}>$. Acesso em: 30 ago. 2010. doi:10.1016/j.jfms.2009.09.012.

LANGSTON, C. Managing fluid and electrolyte disorders in renal failure. Veterinary Clinics of North America: Small Animal Practice, v.38, p 677 -697, 2008.

LEES, G.E. Early diagnosis of renal disease and renal failure. Veterinary Clinics of North America: Small Animal Practice, v.34, p.867-885, 2004.

LEES, G.E. et al. Assessment and management of proteinuria in dogs and cats: 2004 ACVIM Forum Consensus Statement. Journal of Veterinary Internal Medicine, v.19, n.3, p.377$385,2005$.

LUND, E. et al. Health status and population characteristics of dogs and cats examined at private veterinary practices in the United States. Journal American Veterinary Medicine Association, v.214, p.1336-1341, 1999.

MAY, S.N.; LANGSTON, C.E. Managing chronic renal failure. Compendium Veterinary, article 2, p.853-864, 2006.

McGROTTY, Y. Diagnosis and management of chronic kidney disease in dogs and cats. Companion Animal Practice, v.30, p.502-507, 2008

NELSON, R.W.; COUTO, G.C. Small Animal Internal Medicine, St. Louis: Elsevier Saunders, 2009. p.645-659.

PLOTNICK, A. Feline chronic renal failure: long-term medical management. Compendium Veterinary, article 1, jun. 2007.

POLZIN, D.; OSBORNE, C. Conservative medical management of chronic renal failure. In: OSBORNE, C.A.; FINCO, D.R. Canine and feline nephrology and urology. United States of America: Williams \& Wilkins, 1995. p.505-507.

POLZIN, D.J. et al. Insuficiência renal crônica. In: ETTINGER, S.J; FELDMAN, E.C. Tratado de medicina interna veterinária. Rio de Janeiro: Guanabara Koogan, 2004. p.1721-1749.

POLZIN, D.J. et al. Chronic kidney disease. In: ETTINGER, S.J.; FELDMAN, E.C. Textbook of veterinary internal medicine. St. Louis: Elsevier Saunders, 2005. p.1756-1785.

POLZIN, D.J. What is different about chronic kidney disease in cats? In: NESTLÉ PURINA NUTRITIONAL FORUM, 2007, St Louis. Proceedings... St Louis, 2007. p.49-53. (Nutrition Forum Focus on Felines ).

POLZIN, D.J. 11 Guidelines for conservatively treating chronic kidney disease. Veterinary Medicine, peer-reviewed p.788799, 2007. 
POLZIN, D.J. Diagnosing \& staging kidney disease in dogs and cats, 2008. Disponível em: <www.chicagovma.org/ pdfs/ceprograms/CVMA\%20Notes.pdf. Acesso em: $10 \mathrm{fev}$. 2009.

POLZIN, D.J. et al. Calcitriol In: BONAGURA, J.D.; TWEDT, D.C. Kirk's current veterinary therapy XIV. St. Louis: Saunders Elsevier, 2009. p.892-895.

SANDERSON, S.L. Measuring glomerular filtration rate: practical use of clearance tests. In: BONAGURA, J.D.;
TWEDT, D.C. Kirk's current veterinary therapy XIV. St. Louis: Saunders Elsevier, 2009. p 872-879.

SCHRIER, R.W.; REGAL, E.M. Influence of aldosterone on sodium, water and potassium metabolism in chronic renaldisease. Kidney International, v.1, n.3, p.156-168, 1972.

WATSON, A. Indicators of renal insufficiency in dogs and cats presented at a veterinary teaching hospital. Australian Veterinary Practices, v.31, p.54-58, 2001. 